\title{
İş Sağlığı ve Güvenliği Eğitimlerinin Sağlık Sektöründe Güvenlik Kültürü Üzerindeki Etkilerinin Analizi
}

\author{
Ö. Hakan ÇAVUŞ* R Rdvan KESKİN**
}

\begin{abstract}
$\ddot{O} Z$
$\dot{I}_{S ̧}$ sağll $\breve{g} l$ ve güvenliği, işin yapılması sırasında işyerindeki fiziki çevre şartları sebebiyle çalışanların maruz kaldıkları kazalar ile mesleki risklerin azaltılmasını amaçlayan inceleme ve uygulamalar bütünü olarak tanımlanabilmektedir. İs sağlığl ve güvenliği sistemi ile birlikte güvenlik kültürünün oluşturulabilmenin en önemli yöntemi iş sağlı̆̆l ve güvenliği eğitimleridir. Çalışanlar, iş sağliğl ve güvenliği eğitimleri yoluyla elde ettikleri bilgi ve becerileri sonucu çalışmalarında sağllklı ve güvenli davranışlar sergilerler. Ayrıca sağlık sektöründeki ĕgitimler aracılı̆̆ıyla oluşturulacak güvenlik kültürü ile fiziksel, kimyasal, biyolojik ve psiko-sosyal risklerin de azaltılması amaçlanmaktadır. Çalışmanın amacı, iş sağlı̆̆ ve güvenliği eğitimlerinin güvenlik kültürü üzerindeki etkilerinin ölçülmesidir. Yapılan analizler sonucu, soru anketinde kullanılan 22 soru maddesine ait Coronbach's Alpha $(\alpha)$ değerinin 0.927 olarak bulunması anket sorularının kendi içinde tutarlı ve yapılan çalı̧̧mayı çok iyi ölçtüğünü göstermektedir. Ayrıca keşfedici (açılklayıcl) faktör analizi ile elde edilen; "Güvenlik Kurallarl”, "Güvenlik Iletişimi" ve "Güvenlik Ĕ̈itimi" olarak isimlendirilen üç faktöre ait a değerlerinin, faktörlerdeki soru maddelerinin ait olduklarl faktörleri çok iyi temsil ettiğini ve kendi içerisinde de tutarlı olduğunu göstermektedir.

Anahtar Kelimeler: Să̆llk sektörü, iş săğlı̆ açıklayıcı (keşfedici) faktör analizi.
\end{abstract}

JEL Sinıflandirması:H15, K32, J28, C38.

\section{Analysis of the Effects of Occupational Health and Safety Trainings on Safety Culture in the Health Sector}

\begin{abstract}
Occupational health and safety can be defined as a collection of studies and practices aiming at reducing occupational risks and occupational risks due to physical environment in the workplace. Occupational health and safety is the most important method of creating a safety culture together with the occupational health and safety system. Employees demonstrate healthy and safe behaviors by applying knowledge and skills the yacquire through occupational health and safety training to their work. As in other sectors, health care workers are frequently faced with biological, chemical, physical and psychosocial risk factors specific to their sectors. It is aimed to reduce all risks with the security culture to be created through trainings in the health sector. The aim of the study is to measure the effects of occupational health and safety trainings on safety culture. As a result of the analysis, the Coronbach's Alpha $(\alpha)$ value of the 22 question items used in the questionnaire is 0.927, which shows that the survey questions are consistent in itself and measure the work done very well. Also obtained by exploratory (explanatory) factor analysis; It shows that
\end{abstract}

\footnotetext{
*Doç., Dr., Manisa Celal Bayar Üniversitesi İ̈̈BF Çalışma Ekonomisi ve Endüstri İlişkileri Bölümü, ohcavus@gmail.com, ORCID Bilgisi: 0000-0002-0124-8812

** Doç., Dr., Manisa Celal Bayar Üniversitesi İ̈BF Ekonometri Bölümü, brkeskin@ hotmail.com, ORCiD Bilgisi: 0000-0001-5472-0976
} 
the a values of the three factors named as "Safety Rules", "Safety Communication" and "Safety Training" represent the factors of the question items in the factors very well and are consistent within themselves.

Key Words:Health sector,occupational health and safety trainings, safety culture, explanatory factor analysis

JEL Classification: H15, K32, J28, C38.

\section{GİRIŞ}

Uluslararası Çalışma Örgütüne göre, dünyada her yıl dünyada 270 milyon çalışan iş kazası ve 160 milyon işçi meslek hastalıkları sonucu hayatını kaybetmektedir. Türkiye'de iş kazasına bağlı ölümler her geçen yıl artmaktadır ancak meslek hastalıkları sayısal olarak ve tıbbi anlamda neredeyse tespit edilememektedir. İş kazaları ve meslek hastalıkları, çeşitli risk faktörlerinden ve çalışma koşullarından kaynaklanan sorunlar nedeniyle meydana gelmektedir. İş kazaları ve meslek hastalıkları gibi olumsuz sonuçların en önemli nedeni tehlikeli davranışlardır. Bunun da temel nedeni, iş sağlığı ve güvenliği (ISG) konusundaki eğitimsizlik, bilinç eksikliği ve güvenlik kültürünün gelişmemiş olmasıdır (Saraç, 2016).

Güvenlik kültürünün yaygınlaşmasında en etkili politika iş sağlığı ve güvenliği eğitimleridir. Çalışanların ve yöneticilerin İSG yönünden gereken yetenek ve becerilerle donatılmaları çalışanların eğitim almaları yoluyla gerçekleşebilmektedir (Demirbilek, 2015:149-150).

Sağlık sektörü çalışanları sağlı hizmeti sunarken biyolojik, kimyasal, fiziksel ve psiko-sosyal risklere maruz kalmaktadırlar. Uluslararası mevzuatta olduğu gibi sağlık işletmelerinde yapılan işler mevzuatımızda "çok tehlike sınıf" grubunda tanımlanmıştır. Dolayısı ile sağlık işletmelerinde meydana gelen iş kazası ve meslek hastalıklarının doğurduğu sonuçlar, bazen farklı sektörlerde gerçekleşen iş kazası ve meslek hastalıklarının doğurduğu sonuçlardan daha ciddi sonuçlara neden olmaktadır. Konu ile ilgili istatistikler sağlık işletmelerinde iş kazaları ve meslek hastalıklarının gerçekleşme oranının birçok sektörden daha fazla olduğunu ortaya koymaktadır. Sağlık çalışanlarının hizmet sunum süreçlerinde karşılaştıkları riskler sağlı çalışanı yanında hastaları ve genel olarak işletme güvenliğini de tehdit etmektedir (Yorgun ve Atasoy, 2016).

Çalışmamızda sağlık sektöründe faaliyet gösteren özel hastanelerde çalışanlar ile yöneticilerin iş sağlığı ve güvenliğine yönelik algıları, İSG eğitimleri ile ilişkilendirilerek değerlendirilmiştir.

\section{KAVRAMLAR}

İSG eğitimleri ile güvenlik kültürü arasında sıkı bir bağ bulunmaktadır. $\mathrm{Bu}$ bağ tüm sektörlerde faaliyet gösteren işyerleri için geçerlidir. Sağlık sektöründe faaliyet gösteren özel hastanelerde, İSG eğitimleri ile güvenlik kültürü arasındaki etkileşim ele alınırken öncelikle temel kavramların üzerinde durulması gerekmektedir. $\mathrm{Bu}$ temel kavramları; iş sağlığ1 ve güvenliği, iş sağllğ̣ ve güvenliği eğitimleri ve güvenlik kültürü olarak sınıflandırabiliriz. 


\section{A. İş Sağlığı ve Güvenliği}

İSG, bir sistem olarak insanın yaşam hakkı ile doğrudan ilgilidir ve çalışanların, geçici işçilerin, alt-işveren işçilerinin, ziyaretçilerin ve çalışma alanındaki diğer insanların refahını etkileyen faktörler ve şartlar olarak ifade edilmektedir (Seyhan, 2015:80). Diğer bir ifade ile İSG; işyerlerinde iş kazalarının ve meslek hastalıklarının önlenmesi için gerekli bütün faaliyetleri kapsayan bir konu olarak işveren ile işçinin birlikte etkili iletişim, eşgüdüm ve katılımıyla yönetilebilecek bir yapı şeklinde de tanımlanabilmektedir (Kabakçı, 2013:61-62).

Uluslararası Çalışma Örgütü ve Dünya Sağlık Örgütü, iş sağllğı ve güvenliğini; tüm sektörlerde çalışanların fiziksel ve ruhsal sağlıklarını, güvenlikleri ve sosyal refahlarını sağlamak, devam ettirmek ve işin çalışanın fiziksel ve psikolojik yeterliliklerine uygun olması için yapılan çalışmalar şeklinde tanımlanmıştır (Kılkış, 2018:6-7).

ISG çalışmalarının temel amacı, iş hayatında çalışanların sağlığına zarar verebilecek hususların önceden belirlenerek gereken önlemlerin alınması, güvenli bir ortamda çalışmalarının sağlanması, iş kazalarına ve meslek hastalıklarına karşı çalışanların psikolojik ve bedensel sağlıklarının korunmasını sağlamaktır (Devebakan, 2007: 35).

İşkazalarına ve meslek hastalıklarına neden olan hatalar ortaya çıkmadan maruz kalınabilecek risklerin azaltılmasını amaçlayan önleyici İSG yaklaşımının en önemli uygulama basamağını oluşturan eğitim, özellikle çalışanlarda, işverenlerde ve çevreyi oluşturan unsurlarda güvenlik bilincini ve önleme kültürünü geliştirerek sağlıklı ve güvenli çalışma ortamı sağlamaktadır. Buradaki çevre ifadesi, çalışanların kullandığ 1 araç-gereçlerin, çalışma metotlarının, işin organizasyonunun, insanın yapısı, becerileri, yetenekleri arasındaki güçlü ve zayıf yönleriyle olan ilişkisini açıklamaktadır (Serin ve Çuhadar, 2015:56).

\section{B. İş Sağlı̆ğ ve Güvenliği Eğitimleri}

Sanayi Devrimi ile başlayan endüstrileşme sürecinde, çalışanların çalışma koşullarının iyileştirilmesi için yapılan çalışmalar İSG kavramının ortaya çıkmasına neden olmuştur. Zaman içinde disiplinler arası bir gelişme gösteren İSG kavramı günümüzde bağımsız bir bilim dalı haline gelmiştir. İSG; iş kazaları ve meslek hastalıklarının nedenleri, sonuçları ve bunların önlenebilmesi için gerekli olan yöntemleri belirlemeyi ve uygulamayı amaçlayan bir sistemdir. ISG'nin ana hedefi bilimsel veriler 1şığında çalışanlara daha sağlıklı ve daha güvenli bir iş ortamı oluşturmaktır. İSG sistemi teknolojideki gelişmelerden doğrudan etkilendiği için teknolojideki yeni gelişmelere paralel olarak dinamik bir şekilde kendini zorunlu olarak yenilemektedir. İş kazalarına yol açan en önemli nedenin insan faktörü olduğu da göz önüne alınırsa, İSG eğitimlerinin ne denli önemli olduğu ortaya çıkmaktadır (Ceylan, 2012:2).

İş kazalarının büyük bir bölümü, eğitim ve bilgi eksikliği nedeniyle ortaya çıkmaktadır. Bunun sebebi, İSG sistemi hakkında bilgisi olan çalışanların, risk alanlarını tespit edebilmeleri ve oluşabilecek risklerin bilincinde hareket 
etmeleridir. İSG eğitimlerinin verilmesi sürecinde, birçok önemli faktör bulunmaktadır. Bu faktörler (Bilir, 2016:5):

a)İ ş sahasında aktif ve pasif şekilde yer alan çalışanların, iş güvenliği becerisine sahip olmamaları,

b) İşe veya işin belirli bir bölümüne yeni başlayan kişinin, iş güvenliği ile ilgili bilgisinin bulunmamas1,

c) İşletmenin, var olan üretim şeklinin güncel hale getirilerek değiştirilmemesi veya üretimin değiştirilmesi halinde ise çalışanların bu konuda bilgilendirilmemesi,

d)İşcilerin sergilediği performansın, sistematik olarak kayıt altına alınmamas1,

e) Yeni teknolojik uygulama ve cihazların iş sahasında kullanılması durumunda çalışanlara gerekli bilgilerin verilmemesi,

şeklinde açıklanabilir.

İSG eğitimlerinin etkili ve verimli olabilmesi için üç ana unsurun birlikte ele alınması gerekmektedir. Bu unsurlardan ilki, İSG performansı (kurallara uyma, katılım ve çıtıların değerlendirilmesi) ikincisi, işin yapısı (güvenlik iklimi, işyerindeki tehlikeler, kültürel özellikler) ve üçüncüsü de çalışan özellikleridir (İSG ile ilgili bilgiler, güvenlik motivasyonu) (Burke ve Caitlin 2016: 328).

Türkiye'de 6331 sayılı "İş Sağlığı ve Güvenliği Kanunu" kapsamında işverenin yükümlülüğü olarak düzenlenen konulardan birisi de çalışanlara İSG eğitimlerinin verilmesi ve bilgilendirmelerin yapılmasıdır. Güvenlik kültürünün önemli göstergelerinden ve faktörlerinden biri olan güvenlik eğitiminin işletme ihtiyaçlarına uygun süre ve nitelikte sağlanmasının, pozitif güvenlik kültürü oluşumuna katkısı oldukça yüksektir (Arpat, 2015:21).

\section{C. İş Güvenliği Külttürü}

Güvenlik kültürü, örgüt yapısının içinde yer alan çalışanların ve çalışanlardan sorumlu yöneticilerin benimsenmeleri ve eyleme dönüştürmeleri gereken bir olgudur. Güvenliğin sağlanması konusunda devlet dahil olmak üzere tüm taraflar görevlerini yerine getirmek durumundadır. Güvenlik kültürü bilincinin örgüt içerisinde yaygınlaşmaması ve kazalara yönelik gerekli bilgilerin paylaşılmaması kazaların meydana gelmesinin temelini oluşturmaktadır. $\mathrm{Bu}$ sebeple, işverenlerin güvenlik kültürünün oluşturulmasını sağlayarak işletmelerin ve çalışanların menfaati yönünde hareket etmeleri gerekmektedir. Örgütlerde, güvenlik kültürü aracılığıyla, güvenli davranış örüntülerinin oluşturulması sağlanmaktadır (Şahin, 2017:19).

Güvenlik kültürünün oluşturulması için işletme yönetimlerin iş güvenliğini sağlama anlamında taahhüt altına girmesi gerekmektedir. Bu anlamda yönetim; zaman ve kaynak tahsisi yapmalı, İSG kurul toplantılarına katılarak risk sorumluluğu altına girmelidir (Alıc1 ve Alaman, 2017:8).

İş güvenliği kültürü, iş güvenliğinin öncelikli olduğu yaşam biçimidir. İş güvenliği kültürü güvenlik bilgisine dayanır. İş güvenliği; işveren, çalışan veya 
devlet tarafından göz ardı edildiğinde iş kazası ve meslek hastalığı riskleri ortaya çıkar (Arpat, 2015:13). İSG kültürünün yaygınlaştırılması amacıyla "kurumsal üçgen" olarak adlandırılan bir yapının oluşturulması gerekmektedir. Bu sistem; yapı, süreç ve kültür basamaklarından oluşmaktadır. Ayrıca işletmelerde iş güvenliği temelli kurum kültürünü oluşturabilmek için beş ana unsurun da bir araya gelmesi gerekmektedir. Güvenlik kültürünün söz konusu unsurları; tutum ve davranışlardaki değişim, yönetimin taahhüdü, çalışanın ilgisi, promosyon stratejileri, eğitim ve özel kampanyalardan oluşmaktadır. Buna göre işyerlerinde pozitif güvenlik kültürü oluşturma çalışmalarında çalışanların güvensiz tutum ve davranışları değiştirilmelidir. Güvensiz davranışta bulunan çalışanlara yazılı ve sözlü talimatlar tebliğ edilmeli, eğitim verilmeli ve uyarı işaretleri, araç gereç ve aktivite kullanılmalıdır. $\mathrm{Bu}$ anlamda yönetim kaynak, zaman tahsisi yaparak tehlikelerin belirlenmesi sağlar, gerekli güvenlik önlemlerinin alınması için risk sorumluluğuna katılım gösterir ve çeşitli tamamlayıcı tedbirlerle iş güvenliği çalışmalarına katkı sağlar (Yegin, 2015: 55, EASH, 2011:10-11).

İş güvenliği kültürünün oluşumunda yöneticiler, çalışanların sorunlarını dinleyerek tüm çalışanlar için aynı tutarlılıkta davranışlar sergilemelidirler. Çalışanların performansı değerlendirilir, olumlu davranış gösteren her çalışana teşvik amacıyla ödül verme yöntemine başvurulur. Aynı zamanda işyerinde yaşanan tüm kazalar raporlanır, ramak kala olaylar kayıt altına alınır ve kök neden analizleri yapılarak araştırılır ve taraflar bilgilendirilir. Güvenlik kültürünün oluşturulması ve sürdürülmesine yönelik çalışmalarında yönetimin ve çalışanların uzun bir çaba göstermesi beklenir. Güvenlikle ilgili somut amaçlar belirlenmesi, bu amaçlara ulaşımının performans ölçümüyle nitelendirilmesi gerekmektedir (Yegin, 2015: 27).

\section{2. ÖZEL HASTANELERDE ÇALIŞANLARIN KARŞILAŞTIKLARI SAĞLIK VE GÜVENLIKK RİSKLERİ}

Sağlık sektörü, Türkiye'de iş kazaları, meslek hastalıkları ve işe bağlı hastalıklar açısından en riskli sektörlerden birisidir. 26.12.2012-28509 TarihSayılı Resmi Gazete'de yayınlanarak yürürlüğe giren "İş Sağlığı ve Güvenliğine İlişkin Tehlike Sınıfları Tebliğị" uyarınca sağlık sektörü içinde hastane hizmetlerinin çok tehlikeli sınıfa dahil olması nedeniyle sağlık sektöründe faaliyet gösteren işletmelerde İSG'nin önemi daha fazla ön plana çıkmaktadır (Tüzüner ve Özaslan, 2011:144).

Uluslararası Mesleki Sağlık Komisyonu (International Occupational Health Commission) 1990 yılında, sağlik çalışanlarının sağlığının işçi sağlığ yaklaşımı ile ele alınması ve bunun için hastanelerde ilgili birimin kurulması gerektiğini önermiştir (Özkan ve Emiroğlu, 2006:45).

06.04.2011-27897 Tarih-Say1l1 Resmi Gazete'de yayınlanan "Hasta ve Çalışan Güvenliğinin Sağlanmasına Dair Yönetmeliğin" 7. Maddesinde çalışan olarak tanımlanan; "kamu, üniversite ve özel sektör ikinci ve üçüncü basamak să̆llk kurumlarında hizmetin, resmî veya özel sağllk kurumlarında, să̆llk hizmetinin verilmesine iştirak eden bütün sağlık meslekleri mensuplarını ve sağlık meslekleri mensubu olmasa bile sağllk hizmetinin verilmesine sorumlu olarak 
iştirak eden ve hizmetin verilmesine destek sağlayan kimselerin” güvenliğine dair düzenleme yapılmıştır. Söz konusu maddeye göre;

a) Çalışan güvenliği programının hazırlanması,

b) Çalışanlara yönelik sağlık taramalarının yapılması,

c) Engelli çalışanlara yönelik düzenlemelerin yapılması,

ç) Çalışanların kişisel koruyucu önlemleri almasının sağlanması,

d) Çalışanlara yönelik fiziksel saldırıların önlenmesine yönelik düzenleme yapılması,

hususlarında gerekli tedbirleri alınıp düzenlenmesi sağlik kurumlarının görevleri arasında sayılmıştır.

Özel hastanelerde çalışanlar birçok riske maruz kalmaktadırlar. $\mathrm{Bu}$ riskleri; fiziksel, biyolojik, kimyasal ve psiko-sosyal risk etmenleri şeklinde sıralayabiliriz. Fiziksel risk etmenleri; aydınlatma, 1s1, temizlik, havalandırma, gürültü, otopark, bekleme odaları, dış görünüm, radyoaktif alanlar vb özellikleri kapsamaktadır (Taşdemir, vd., 2015:6). Biyolojik risk etmenleri; 15.06.201328678 Tarih-Sayılı Resmi Gazete'de yayınlanan "Biyolojik Etkenlere Maruziyet Risklerinin Önlenmesi Hakkında Yönetmeliğin" 4. maddesine göre, "herhangi bir enfeksiyona, alerjiye veya zehirlenmeye neden olabilen, genetik olarak değiştirilmiş olanlar da dâhil mikroorganizmaları, hücre kültürlerini ve insan endoparazitleri" olarak tanımlanmıştır. Kimyasal risk etmenleri; sağlik çalışanlarının yoğun olarak karşılaştığı kimyasal tehlike ve riskler, deterjan, anestetik gazlar, sterilizenler, dezenfektanlar, kimyasal sterilize ajanlar ve ilaçlar olarak sıralanabilir. Gerekli tedbirler alınmadığında sağlık açısından olumsuz etkilere sebep olan bu kimyasal maddeler özellikle ameliyathane ve laboratuvarlarda daha yoğun risk oluşturmaktadır (Bulut, 2016:21). Psiko-sosyal risk etmenleri; işyerinde şiddet, saldırı, fiili taciz, tehdit, eşyaya zarar verme, mobing gibi suç teşkil eden davranışlar sonucu ortaya çıkmaktadır.

\section{ISS SAĞLIĞI VE GÜVENLIĞİ KANUNUNA GÖRE VERILEN İŞ SAĞLIĞI VE GÜVENLİĞİ EĞITTIMLERİ}

Türkiye'de İSG eğitimleri temel olarak 6331 Sayılı Kanun'un 17. maddesinde ve 15.05.2013-28648 tarih-sayılı Resmi Gazete'de yayınlanarak yürürlüğe giren "Çalışanların İş Sağlığı ve Güvenliği Eğitimlerinin Usul ve Esasları Hakkında Yönetmelik" (İSGE Yönetmeliği) kapsamında ayrıntılı olarak düzenlenmiştir. İSGE Yönetmeliği'nin dışında da spesifik İSG eğitimleri farklı yönetmeliklerde düzenlenmiştir. 6331 Sayılı Kanun ve bu Kanun'a göre yayınlanan İSGE Yönetmeliğinde, İSG eğitimlerinin içeriği, esasları, süresi, periyodu ve eğiticilerin nitelikleri açıkça düzenlenmiştir. 6331 sayılı Kanun'un 4. maddesinde, işverenin çalışana karşı genel yükümlülükleri arasında belirtilen İSG eğitimi, Kanun'un 17.maddesinde "Çalışanların Eğitimi" başlığı altında daha ayrıntılı şekilde hükme bağlanmıştır. Maddeye göre; "işveren, çalışanların ISG ĕgitimlerini almasını sağlayacaktır. Bu ĕgitim özellikle; işe başlamadan önce, çalışma yeri veya iş değişikliğinde, iş ekipmanının değişmesi hâlinde veya yeni teknoloji uygulanması hâlinde verilecektir. Eğitimler, değişen ve ortaya çıkan 
yeni risklere uygun olarak yenilenir, gerektiğinde ve düzenli aralıklarla tekrarlanmalıdır".

Ayrica;

“a) Çalışan temsilcileri özel olarak ĕ̌itilecektir.

b) Mesleki eğitim alma zorunluluğu bulunan tehlikeli ve çok tehlikeli sınıfta yer alan işlerde, yapacă̆ı işle ilgili mesleki ĕ̆itim aldı̆̆ını belgeleyemeyenler çalıştırılamayacaktır.

c) Iş kazası geçiren veya meslek hastalığına yakalanan çalışana işe başlamadan önce, söz konusu kazanın veya meslek hastalı̆̆ının sebepleri, korunma yolları ve güvenli çalışma yöntemleri ile ilgili ilave eğitim verilerek herhangi bir sebeple altı aydan fazla süreyle işten uzak kalanlara, tekrar işe başlatılmadan önce bilgi yenileme eğitimi verilecektir.

d) Tehlikeli ve çok tehlikeli sınıfta yer alan işyerlerinde; yapılacak işlerde karşılaşılacak sağlık ve güvenlik riskleri ile ilgili yeterli bilgi ve talimatları içeren ĕ̆itimin alındı̆̆ına dair belge olmaksızın, başka işyerlerinden çalışmak üzere gelen çalışanlar işe başlatılamayacaktır.

e) Geçici iş ilişkisi kurulan işveren, iş să̆lı̆̆ ve güvenliği risklerine karşı çalışana gerekli eğitimin verilmesini sağlayacaktır."

Söz konusu 17. madde kapsamında verilecek eğitimin maliyeti çalışanlara yansıtılamayacak ve eğitimlerde geçen süre çalışma süresinden sayılacaktır.

6331 Sayılı Kanun'un "Çalışanların bilgilendirilmesi” başlıklı 16. maddesinde, işverenin çalışanlara İSG riskleri, bunlara karşı alınan tedbirler, acil durumlar için görevlendirilen kişiler hakkında eğitim vermesi gerektiği belirtilmektedir.

İSGE Yönetmeliğinin 4. maddesinde eğitimler; "işe başlama eğitimi, temel ĕgitim ve uzaktan ĕgitim” olmak üzere üç farklı şekilde düzenlenmiştir. İşe başlama eğitimi, "çalışanın fiilen çalışmaya başlamadan önce, çalışanın yapacă̆ işe, varsa kullanacă̆ iş ekipmanına ve işyerine özgü iş să̆liğl ve güvenliği tedbirlerini içeren konularda uygulamall olarak verilen eğitimi", içermektedir. İkinci eğitim türü olan temel eğitim, "İSGE Yönetmeliğinin ekinde yer alan Asgari Ek-1'de belirtilen konulart içeren ve düzenli aralıklarla tekrarlanan eğitimi” tanımlamaktadır. Son olarak düzenlenen uzaktan eğitim, "iletişim teknolojileri aracılı̆̆ıla elektronik ortamda gerçekleştirilen ĕgitim faaliyetlerini” ifade etmektedir. Temel eğitim (ISSE Yönetmeliği Ek:1), her çalışanın her işyerinde karşılaşabileceği genel risklere, İSG mevzuatı ve çalışanın hak ve sorumluluklarına ilişkin konular asgari eğitim içeriği olarak belirlenmiş ve ilgili Yönetmelikte temel eğitim dört ana başlık altında düzenlenmiştir. Buna göre eğitim konu başlıkları; "1. Genel konular (Çalışma mevzuatı ile ilgili bilgiler, çalışanların yasal hak ve sorumlulukları, işyeri temizliği ve düzeni, iş kazası ve meslek hastalığından doğan hukuki sonuçlar), 2. Să̆lık konuları (Meslek hastaliklarının sebepleri, hastaliktan korunma prensipleri ve korunma tekniklerinin uygulanmast, biyolojik ve psikososyal risk etmenleri, ilkyardım, tütün ürünlerinin zararlarl ve pasif etkilenme), 3. Teknik konular ( Kimyasal, fiziksel ve ergonomik risk etmenleri, elle kaldırma ve taşıma, parlama, patlama, yangın ve yangından korunma, iş ekipmanlarının güvenli kullanımı, ekranlı araçlarla çalışma, elektrik, tehlikeleri, riskleri ve önlemleri, iş kazalarının 
sebepleri ve korunma prensipleri ile tekniklerinin uygulanması, güvenlik ve sağllk işaretleri, kişisel koruyucu donanım kullanımı, iş să̆lı̆̆ ve güvenliği genel kuralları ve güvenlik kültürü, tahliye ve kurtarma), 4. Diğer konular (çalışanın yaptı̆̆ işe özgü yüksekte çalı̧̧ma, kapalı ortamda çalışma, radyasyon riskinin bulunduğu ortamlarda çalışma, kaynakla çalışma, özel risk taşıyan ekipman ile çalışma, kanserojen maddelerin yol açtı̆̆ olası să̆lık riskleri ve benzeri)" olarak düzenlenmiştir.

İSGE Yönetmeliğinin 11. maddesinde eğitim süreleri düzenlenmiştir. Söz konusu maddeye göre, "çalışanlara verilecek temel eğitimler, işin devamı süresince belirlenen düzenli arallklar içinde; a) Az tehlikeli işyerleri için en az sekiz saat, b) Tehlikeli işyerleri için en az on iki saat ve c) Çok tehlikeli işyerleri için en az on altı saat olarak her çalışan için düzenlenmesi zorunludur." Yine ilgili Yönetmeliğin 6/4. Maddesine göre, "değişsen ve ortaya çıkan yeni riskler de dikkate alınarak eğitimler; a) Çok tehlikeli sinıfta yer alan işyerlerinde yılda en az bir defa, b) Tehlikeli sinifta yer alan işyerlerinde iki yılda en az bir defa ve c) Az tehlikeli sinıfta yer alan işyerlerinde üç yılda en az bir defa tekrarlanmalıdır."

Özel hastaneler çok tehlikeli sinıfta yer almaktadırlar. Bu durumda hastane çalışanlarının ayrıca mesleki eğitim alma zorunlulukları bulunmaktadır. Mesleki eğitim zorunluluğunun aranmasında çalışanın işyerinin tehlike sınıfı değil, çalışanın yaptığı iş esas alınmaktadır. Bu işler de ilgili 13.07.2013-28706 Tarih-Sayılı Resmi Gazetede yayınlanan "Tehlikeli ve Çok Tehlikeli Sınıfta Yer Alan İşlerde Çalıştırılacakların Mesleki Eğitimlerine Dair Yönetmelik” ekinde belirtilen işlerdir. İşyeri çok tehlikeli veya tehlikeli sınıfta yer alsa da çalışanın yaptığı iş yönetmeliğin ekinde sayılan işlerden değilse, 6331 Sayılı Kanun kapsamında çalışan için mesleki eğitim zorunluluğu bulunmamaktadır.

\section{UYGULAMA}

İş güvenliği kültürü ile ilgili olarak yapılmış temel çalışmalar bulunmaktadır. Bu çalışmalar içerisinde sağlık sektöründe iş güvenliği kültürünün alt boyutlarıyla birlikte ele alındığı iki önemli çalışma bulunmaktadır. Bu çalışmalardan; Yorgun ve Atasoy (2015) yaptıkları çalışmada, enfeksiyonları önleme, yönetim politikaları, sağlı taramaları, kimyasal madde güvenliği, güvenlik eğitimleri, şiddeti önleme, gıda güvenliği ve düşmeyi önleme olmak üzere sekiz alt boyut içeren bir güvenlik kültürü ölçeği kullanılmıştır. Öztürk ve Babacan (2012) yapmış olduğu diğer çalışmada ise, mesleki hastalıklar ve şikâyetler, sağlık taraması ve kayıt sistemleri, kazalar ve zehirlenmeler, yönetsel destek ve yaklaşımlar, malzeme, araç ve gereç denetimi, koruyucu önlemler ve kurallar, fiziksel ortam uygunluğu olmak üzere yedi alt boyut içeren bir güvenlik kültürü ölçeği kullanılmıştır. Sağlık sektörü dışındaki sektörlerde iş güvenliği ile ilgili yapılan çalışmalardan Genel olarak güvenlik kültürünün ele alındığı çalışmalar da bulunmaktadır. Özkan ve Arpat (2015) yaptıkları çalışmada, güvenlik kuralları, güvenlik önceliği, yönetimin güvenlik bağlılı̆̆ı, güvenlik eğitimi, güvenlik liderliği, güvenlik teşviki, güvenlik iletişimi, güvenlik farkındalığı, çalışanların katılımı, güvenlik davranışları ve proses güvenliği olmak üzere on bir boyut içeren ölçek kullanırken, Yıldız ve Yılmaz (2017) 
yaptıkları çalışmada, yönetimin bağl1lı̆̆1, güvenlik önceliği, güvenlik iletişimi, güvenlik eğitimi, güvenlik farkındalı̆̆ı/yetkinlik, çalışanların katılımı, kadercilik, raporlama kültürü, güvenli davranış ve güvenlik katılımı olmak üzere on alt boyut içeren bir güvenlik kültürü ölçeği kullanmışlardır. Ayrıca başka bir çalışmada, literatürdeki farklı ölçeklerden oluşturulan anketle sekiz güvenlik kültürü boyutu üzerinden, tekstil sektöründe faaliyette bulunan bir firmada çalışan iki yüz elli işçi ile gerçekleştirilmiştir (Demirbilek, 2005:158-160).

Alana yönelik anket çalışmamızda yukarıda bahsedilen çalışmalar esas alınarak daha büyük bir örneklem kullanılmış ve İSG eğitimlerinin güvenlik kültürü üzerindeki etkileri araştırılmıştır. Bunun için de güvenlik kültürü ölçeklerinde yer alan ve güvenlik kültürünü önemli düzeyde etkileyen alt boyutlara yönelik sorulardan faydalanılmıştır.

\subsection{Veri Seti ve Örneklem Büyüklüğü}

$\mathrm{Bu}$ çalışmada anket tekniği kullanılarak veriler elde edilmiştir. Anket iki kısımdan oluşmaktadır. Birinci kısımda çalışanların demografik bilgileri ve meslekleri ile ilgili 8 soru, ikinci kısmında İSGE'yi ölçmeye yönelik 22 soru maddesi bulunmaktadır. Anket soruları hazırlanırken literatürde yer alan ISG güvenlik kültürü ile ilgili çalışmalar kullanılmıştır. Ana kütleyi oluşturan çerçeve beş özel hastanede çalışan 1598 sağlık çalışanları ile sınırlandırılmıştır. $\mathrm{Bu}$ çalışmanın örneklem hacmi, basit rassal örneklem yöntemi ile \%98 güven seviyesi ve 0,05 anlam düzeyi alınarak hesaplanmıştır. Böylece örneklem büyüklügünün en az 405 kişi olması gerektiği belirlenmiştir. $\mathrm{Bu}$ amaç doğrultusunda 450 kişiye ilgili anket soru maddeleri uygulanmış ancak yapılan anketlerden 31 anket formunda eksik bilgilere rastlanıldığ 1 için değerlendirmeye alınmamıştır.

\subsection{Veri Analiz Yöntemi ve Bulgular}

Yapılan bilimsel çalışmalarda veri toplama aracı olarak anket kullanıldığında, anket soru maddelerinin geçerliliği ve güvenilirliği sağlaması oldukça önemlidir. Anket soru maddelerinin geçerliliğini sağlamak amacıyla İSG uzmanı kişilerden anket soru maddeleri hakkında görüş alınarak gerekli düzeltme işlemleri yapılıp anketin geçerliliği sağlanmıştır. Anket soru maddelerinin güvenilirliği test etmek amaciyla da Coronbach's Alpha $(\alpha)$ olarak bilinen test değerine bakılarak karar verilmiştir. Bu bilimsel çalışılmada anketteki 22 soru maddesi (demografik özelliklere ait anket soruları çıkartılmıştır) kullanılarak elde edilen Coronbach's Alpha değeri 0.927'dir. $\alpha$ değerinin 0.70'den büyük olması anket soru maddelerinin kendi içinde tutarlı ve ilgilenilen konuyu çok iyi ölçtüğünü göstermektedir (Gürbüz ve Şahin, 2014:156).

Anket soru maddelerinin istatistiksel analizlerinde aşağıdaki adımlar izlenmiştir.

1. Adım: Ankete katılanlara ait frekans dağılım tablosunun gösterimi ve yorumu,

2. Adım: Anket soru maddelerinin daha kolay anlaşılması, yorumlanması ve test edilmesi amaciyla alt boyutların (faktörlerin)oluşturulmasında kullanılan keşfedici faktör analiz sonuçlarının sunumu ve açıklaması, 
3. Adım: Anketteki demografik özelliklerle, elde edilen faktörler arasındaki ilişkilerin test edilmesi.

Anket verilerinin istatistiksel analizinde Statistical Package for Social Sciences (SPSS 22) bilgisayar programı kullanılmıştır. Ankete katılan 419 sağlık personelinin demografik özelliklerine ait frekans dağılımları aşağıdaki tabloda verilmiştir.

1. Adım: Ankete katılanlara ait frekans dağılım tablosunun gösterimi ve yorumu:

Tablo1. İSGE Anketine Katılanlara ait Frekans Dağılım

\begin{tabular}{|c|c|c|c|c|c|}
\hline Yaş & $\begin{array}{c}\text { Frekans } \\
\text { (N) }\end{array}$ & $\begin{array}{c}\text { Yüzde } \\
(\%)\end{array}$ & Cinsiyet & $\begin{array}{l}\text { Frekans } \\
\text { (N) }\end{array}$ & $\begin{array}{c}\text { Yüzde } \\
(\%)\end{array}$ \\
\hline $18-24$ & 94 & 22.4 & Erkek & 156 & 37.4 \\
\hline $25-31$ & 106 & 25.3 & Kadın & 261 & 62.6 \\
\hline $32-38$ & 82 & 19.6 & Toplam & 417 & 100 \\
\hline $39-45$ & 52 & 12.4 & Medeni Durumu & $\mathbf{N}$ & $\%$ \\
\hline $46-52$ & 45 & 10.7 & Evli & 225 & 54.6 \\
\hline $53+$ & 40 & 9.5 & Bekar & 187 & 45.4 \\
\hline Toplam & 419 & 100 & Toplam & 412 & 100 \\
\hline Meslek & $\mathbf{N}$ & $\%$ & Eğitim Durumu & $\mathbf{N}$ & $\%$ \\
\hline Hekim/Doktor & 43 & 10.4 & İlköğretim & 39 & 9.3 \\
\hline Hemşire/Ebe & 108 & 26.1 & Lise & 159 & 37.9 \\
\hline Teknik Personel & 59 & 14.3 & Ön lisans/ Lisans & 170 & 40.6 \\
\hline İdari Personel & 57 & 13.8 & Yüksek Lisans / Doktora & 51 & 12.2 \\
\hline Diğer & 147 & 35.5 & Toplam & 419 & 100 \\
\hline Toplam & 414 & 100 & & & \\
\hline
\end{tabular}

Tablo 1'e göre; ankete katılanların yaş grupları incelendiğinde yaklaşık olarak \% 25 oranla 25-31 yaş grubu birinci, \% 22 oranla 18-24 yaş grubu ikinci ve \% 20 oranla da 32-38 yaş grubu üçüncü sırada yer almaktadır. Katılımcıların \% 63'ü kadın, \% 37'si erkektir. Katılımcıların meslek frekanslarına bakıldığında $\% 10$ oranında hekim/doktor, \% 26 oranında hemşire/ebe'lerin, \% 14 oranla teknik ve idari personel ve $\% 36$ oranında da hastanelerde görev yapan diğer elemanların yer aldığı anlaşılıyor. Medeni durum bakımından katılımcıların \% 55'i evli iken \% 45'i bekârdır. Katılımcıların eğitim durumları bakımından \% 12 'si yüksek lisans/doktora, \% 41'i ön lisans/lisans, \% 38'i lise ve \% 9'u ilköğretim mezunudur.

2. Adım: Anket soru maddelerinin daha kolay anlaşılması, yorumlanması ve test edilmesi amacıyla alt boyutların (faktörlerin) oluşturulmasında kullanılan keşfedici faktör analiz sonuçlarının sunumu ve açıklaması:

Çalışmada kullanılan anket soru maddelerine Keşfedici faktör analizinin uygulanıp uygulanmayacağı KMO (Kaisen-Meyer-Olkin) ve Bartlett Küresellik test değerlerine bakılarak değerlendirilir. KMO testi örneklem büyüklügünün faktör analizine uygun olup olmadığını ölçmeye yarayan bir test iken Bartlett Küresellik testi ise soru maddelerine ait korelasyon matrisinin faktör analizine 
uygun olup olmadığını ölçmeye yarayan bir testi. Soru maddesine ait KMO test değeri 0.943 ve Bartlett Küresellik testine ait $p$ değeri 0.00 olarak hesaplanmıştır. Bu değerden ilkinin 0.60 ve üstünde olması örneklem büyüklüğünün, ve ikincinin " $p$ " değerinin 0.05 'den küçük çıkması da soru maddelerine ait korelasyon matrisinin faktör analizine uygun olduğunu göstermektedir. KFA'de faktör sayının belirlenmesinde ya faktörlere ait özdeğerlere ya da grafiğine bakılarak karar verilir. Ayrıca elde edilecek faktörlerin daha iyi adlandırılması, anlaşılması ve yorumlanabilmesi içi rotasyon işlemi yapılır. Bu çalışmada en çok kullanılan "Varimax Rotasyon" yöntemi kullanılmıştır. Tablo 2'de faktör sayısının belirlenmesinde kullanılan özdeğerler ve rotasyon sonrası elde edilen faktörlere ait toplam açıklanan varyans yüzdeleri yer almaktadır.

Tablo 2. Faktör Sayısı ve Varyans Açıklama Yüzdesi (\%)

\begin{tabular}{|c|c|c|c|c|c|}
\hline \multirow{2}{*}{ Faktörler } & \multicolumn{3}{|c|}{ Başlangıç Özdeğerler } & \multicolumn{3}{|c|}{ Döndürme Sonrası Fak törlere ait Değerler } \\
\cline { 2 - 6 } & Toplam & $\begin{array}{c}\text { Varyans } \\
(\%)\end{array}$ & Toplam & $\begin{array}{c}\text { Varyans } \\
(\%)\end{array}$ & $\begin{array}{c}\text { Toplam Açılanan } \\
\text { Varyans (\%) }\end{array}$ \\
\hline 1 & 10.522 & 47.829 & 5.481 & 24.912 & 24.912 \\
\hline 2 & 2.017 & 9.168 & 4.312 & 19.602 & 44.514 \\
\hline 3 & 1.367 & 6.215 & 4.114 & 18.698 & 63.212 \\
\hline
\end{tabular}

Özdeğerlere bakılarak faktör sayısına karar verilirken, özdeğeri 1'den büyük olan faktörler seçilir. Tablo 2'nin ikinci sütunu incelendiğinde faktör sayısının 3 olduğu anlaşılmaktadır. Tablo 2'nin son sütununda ise bu üç faktöre ait rotasyon sonrası toplam açılanan varyans yüzdelerinin kümülatif toplamları yer almaktadır. Buna göre bu üç faktör toplam varyansın \% 63.312'sini açıklamaktadır. Genel bir kural olmamakla birlikte toplam varyans açıklama oranının \% 50'nin üzerinde olması beklenir (Gürbüz ve Şahin, 2014:292).

Elde edilen faktörlerin isimlendirildiği, hangi faktörde hangi soru maddesinin yer aldığının gösterildiği, bu soru maddelerine karşılık gelen faktör yük değerlerinin ve faktörlere ait Coranbach's Alpha değerlerinin bulunduğu tablo aşağıda yer almaktadır. Tablo 3'ün ilk sütununda faktör 1 , faktör 2 ve faktör 3 sırasıyla; "Güvenlik kuralları", "Güvenlik İletişimi” ve "Güvenlik Eğitimi”" olarak isimlendirilmişlerdir. İlgili tablonun ikinci sütununda her bir faktörün kapsadığ1 soru maddeleri ve üçüncü sütunda ise bu soru maddelerinin faktör yükleri yer almaktadır. Buna göre faktör 1 dokuz soru maddesinden, faktör 2 sekiz soru maddesinden ve faktör 3 beş soru maddesinden oluşmaktadır. Tablo 3'nin son sütununda ise dokuz soru maddesinden oluşan faktör 1'in $\alpha$ katsayısı 0.918, sekizi soru maddesinden oluşan faktör 2'nin $\alpha$ katsayısı 0.885 ve beş soru maddesinden oluşan faktör 3'ün $\alpha$ katsayısı 0.873 olarak hesaplanmıştır. Tüm faktörlere ait $\alpha$ katsayılarının 70'den büyük olması faktörlerdeki soru maddelerinin kendi aralarında da tutarlı ve söz konusu faktörleri çok iyi temsil ettiğini göstermektedir. 
Tablo 3. Faktörlere ait Özellikler

\begin{tabular}{|c|c|c|c|}
\hline $\begin{array}{c}\text { Faktör } \\
\text { Numarası } \\
\text { ve İsmi }\end{array}$ & Anket Soru Maddeleri & $\begin{array}{l}\text { Faktör } \\
\text { Yükleri }\end{array}$ & $\begin{array}{c}\text { Coranbach's } \\
\text { Alpha } \\
\text { Değerleri }\end{array}$ \\
\hline \multirow{9}{*}{ 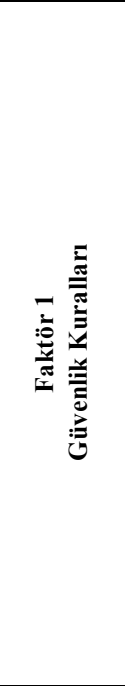 } & $\begin{array}{l}\text { 29.Koruyucu ekipmanlara (eldiven, gözlük vb.), rahat şekilde } \\
\text { ulaşılabilmektedir. }\end{array}$ & 0.799 & \multirow{9}{*}{0.918} \\
\hline & 26.Kan vb. sıvıları korumak için önlemler alınmaktadır. & 0.791 & \\
\hline & 25.Toksik, tıbbi atıklar vb. için önlemler alınmaktadır. & 0.752 & \\
\hline & 30.Kesici ve delici araçlar için uygun ekipman bulunmaktadır. & 0.749 & \\
\hline & $\begin{array}{l}\text { 28. Kimyasal madde ve solüsyonları hazırlamada, uygun önlemler } \\
\text { alınmaktadır. }\end{array}$ & 0.738 & \\
\hline & $\begin{array}{l}\text { 24.Çalışılan tüm birimlerin temizlik, hijyen ve izolasyon talimatları } \\
\text { yazılı olarak belirlenmiştir. }\end{array}$ & 0.722 & \\
\hline & $\begin{array}{l}\text { 27.Özel ilaçlar (Kemoterapi vb.) için , özel talimatlar } \\
\text { uygulanmaktadır. }\end{array}$ & 0.672 & \\
\hline & 23. Çalışanlara, belirli periyotlarla, sağlık taraması yapılmaktadır. & 0.614 & \\
\hline & $\begin{array}{l}\text { 20.İş kazaları ve meslek hastalıklarına yönelik, bildirim ve kayıt } \\
\text { formları tutulmaktadır. }\end{array}$ & 0.527 & \\
\hline \multirow{8}{*}{ 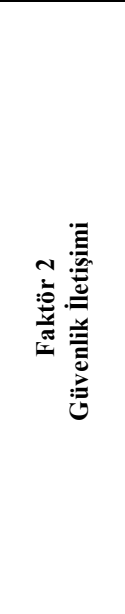 } & $\begin{array}{l}\text { 18.Çalışanlar, çalışma koşullarında aksaklıklar gördüklerinde, yazılı } \\
\text { önerilerde bulunurlar. }\end{array}$ & 0.774 & \multirow{8}{*}{0.885} \\
\hline & 17.Çalışanlar, güvenlik yönetmeliklerine uymaktadırlar. & 0.745 & \\
\hline & $\begin{array}{l}\text { 19.İstenmeyen durumları bildirme amacıyla, bir raporlama sistemi } \\
\text { oluşturulmuştur. }\end{array}$ & 0.737 & \\
\hline & $\begin{array}{l}\text { 16.Çalışanlar, iş sağlığı ve güvenliği konusunda paylaşımda } \\
\text { bulunurlar. }\end{array}$ & 0.676 & \\
\hline & $\begin{array}{l}\text { 15.İşin gerektirdiği güvenlik kuralları, çalışanlar tarafından } \\
\text { bilinmektedir. }\end{array}$ & 0.612 & \\
\hline & 22.Çalışanlar, "Ramak Kala " olayları bildirmeye isteklidir. & 0.604 & \\
\hline & 13. Çalışanlar, hastanede güvenlik kurallarına her zaman uyarlar. & 0.562 & \\
\hline & $\begin{array}{l}\text { 21.Çalışanlar, gerçekleşen kazaları ve olayları her zaman } \\
\text { bildirmektedir. }\end{array}$ & 0.523 & \\
\hline \multirow{5}{*}{ 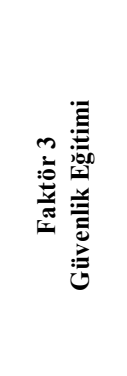 } & $\begin{array}{l}\text { 12.Güvenlik kültürünü geliştirmek amacıyla, yeterli düzeyde eğitim } \\
\text { gerçekleştirilmektedir. }\end{array}$ & 0.759 & \multirow{5}{*}{0.873} \\
\hline & $\begin{array}{l}\text { 10.Hastane yönetimi, iş sağlığı ve güvenliği konusunda, çalışanlarla } \\
\text { işbirliği yapar. }\end{array}$ & 0.731 & \\
\hline & $\begin{array}{l}\text { 11.Çalışan katılımı ve bağlılığı, güvenlik faaliyetlerinin temeli } \\
\text { olarak görülmektedir. }\end{array}$ & 0.729 & \\
\hline & 9.İş Sağlığı ve Güvenliği eğitimlerine öncelik verilmektedir. & 0.696 & \\
\hline & $\begin{array}{l}\text { 14.Hastanede, güvenliğin iyileştirilmesini sağlayacak etkinlikler } \\
\text { düzenlenir. }\end{array}$ & 0.634 & \\
\hline
\end{tabular}


3. Adım: Anketteki demografik özelliklerle, elde edilen faktörler arasındaki ilişkilerin test edilmesi:

Ankete katılanların demografik özellikleri KFA sonucunda elde edilen F1, F2 ve F3ile anlamlı farkl1lıkların olup olmadığ $t$ testi ve anova test istatistikleri ile araştırılmıştır.

Ankette iki bağımsız grubu olan cinsiyet ve medeni durumun ortalamaları arasındaki farkın anlamlı olup olmadığı "Bağımsız iki örnek t test" istatistiği ile araştııılmıştır. Ankete katılanların cinsiyetleri dikkate alınarak kurulan sıfır hipotezler aşağıda verilmiştir.

$\mathrm{H}_{01}$ : Cinsiyet bakımından "Güvenlik Kuralları Faktörüne (F1)" ilişkin görüşlerde anlamlı bir farklılık yoktur.

$\mathrm{H}_{02}$ : Cinsiyet bakımından "Güvenlik İletişimi Faktörü (F2)" ilişkin görüşlerde anlamlı bir farklılık yoktur.

$\mathrm{H}_{03}$ : Cinsiyet bakımından "Güvenlik Eğitimi Faktörü (F3)" ilişkin görüşlerde anlamlı bir farklılık yoktur.

Bu hipotezlere ait t test sonuçları Tablo 4'te verilmiştir.

Tablo 4. $t$ Test Sonuçları

\begin{tabular}{|l|l|l|l|}
\hline Hipotezler & & $\mathbf{d}^{*}$ & \\
\hline $\mathrm{H}_{01}$ & 2.283 & 15 & 0.023 \\
\hline $\mathrm{H}_{02}$ & 0.289 & 445 & 0.773 \\
\hline $\mathrm{H}_{03}$ & 0.446 & 445 & 0.057 \\
\hline
\end{tabular}

Tablo 4'e göre $\mathrm{H}_{01}$ hipotezine ait olasıllk değeri $0.023<0.05$ olduğu için $\mathrm{H}_{01}$ hipotezi reddedilmiştir. Buna göre cinsiyet bakımından "Güvenlik Kuralları" faktörüne ilişkin görüşlerde anlamlı bir farklılık vardır. Buna karşılık $\mathrm{H}_{02}$ ve $\mathrm{H}_{03}$ hipotezlerine ait olasılık değeri $\mathrm{p}>0.05$ olduğu için $\mathrm{H}_{02}$ ve $\mathrm{H}_{03}$ hipotezleri kabul edilmiştir. Yani ankete katılanların cinsiyetleri bakımından "Güvenlik İletişimi" ve "Güvenlik Eğitimi" faktörlerine ilişkin anlamlı bir farklılık yoktur.

Ankete katılanların medeni durumları dikkate alınarak kurulan sıfir hipotezler aşağıda verilmiştir.

$\mathrm{H}_{01}$ : Medeni durumu bakımından F1'e ilişkin görüşlerde anlamlı bir farklilik yoktur.

$\mathrm{H}_{02}$ : Medeni durumu bakımından F2'ye ilişkin görüşlerde anlamlı bir farkl111k yoktur.

$\mathrm{H}_{03}$ : Medeni durumu bakımından F3'e ilişkin görüşlerde anlamlı bir farkl1l1k yoktur.

$\mathrm{Bu}$ hipotezlere ait $\mathrm{t}$ test sonuçları Tablo 5'te verilmiştir.

Tablo 5. $t$ Test Sonuçları

\begin{tabular}{|l|l|l|l|}
\hline \multicolumn{1}{|c|}{ Hipotezler } & & $\mathbf{d}^{*}$ & \\
\hline $\mathrm{H}_{01}$ & 1.527 & 410 & 0.127 \\
\hline $\mathrm{H}_{02}$ & 0.139 & 410 & 0.889 \\
\hline $\mathrm{H}_{03}$ & -1.112 & 410 & 0.267 \\
\hline
\end{tabular}


Tablo 5'e göre $\mathrm{H}_{01}, \mathrm{H}_{02}$ ve $\mathrm{H}_{03}$ hipotezlerine ait olas1lık değerleri 0.05 'den büyük olduğu için $\mathrm{H} 01, \mathrm{H}_{02}$ ve $\mathrm{H}_{03}$ hipotezleri kabul edilmiştir. Yani ankete katılanların medeni durumları bakımından F1, F2 ve F3 faktörlerine ilişkin anlamlı bir farklılik yoktur.

Ankette üç ve daha fazla bağımsız grubu olan yaş (6 grup), meslek (5 grup) ve eğitim durumları (4 grup) ortalamaları arasındaki farkın anlamlı olup olmadığ1 "ANOVA" test istatistiği ile araştırılmıştır. Ankete katılanların yaş, meslek ve eğitim durumları dikkate alınarak kurulan sıfır hipotezler aşağıda verilmiştir.

$\mathrm{H}_{01}$ : Yaş grupları bakımından F1'e ilişkin görüş farklılığı yoktur.

$\mathrm{H}_{02}$ : Yaş grupları bakımından F2'ye ilişkin görüş farklılığ1 yoktur.

$\mathrm{H}_{03}$ : Yaş grupları bakımından F3'e ilişkin görüş farklılığ1 yoktur.

$\mathrm{H}_{04}$ : Meslek grupları bakımından F1'e ilişskin görüş farklılığ1 yoktur.

$\mathrm{H}_{05}$ : Meslek grupları bakımından F2'ye ilişkin görüş farklılığ 1 yoktur.

$\mathrm{H}_{06}$ : Meslek grupları bakımından F3'e ilişkin görüş farklılığı yoktur.

yoktur.

$\mathrm{H}_{07}$ : Mezuniyet derece gruplar bakımından F1'e ilişkin görüş farklılığı yoktur.

$\mathrm{H}_{08}$ : Mezuniyet derece gruplar bakımından F2'ye ilişkin görüş farklılığ1

$\mathrm{H}_{09}$ : Mezuniyet derece gruplar bakımından F3'e ilişkin görüş farklılığı yoktur.

Anova test istatistiğinin doğru olarak yorumlanabilmesi için grup varyanslarının homojenliği varsayımını sağlaması gerekmektedir. Bunun için " $\mathrm{H}_{0}$ : Grup varyansları homojendir (eşittir)" şeklindeki kurulan sıfır hipotezinin kabul edilmesi gerekir. Bu hipotez levene test istatistiği ile test edilir. Tablo 6'da ilgili hipotezlere ait levene ve anova test istatistik sonuçları yer almaktadır.

Tablo 6. ANOVA Test sonuçları

\begin{tabular}{|c|c|c|c|c|c|c|c|c|c|c|}
\hline \multirow{2}{*}{$\begin{array}{c}\text { Levene test } \\
\text { İstatistiği }\end{array}$} & \multirow{2}{*}{ sd1 } & \multirow{2}{*}{$\mathrm{sd} 2$} & \multirow{2}{*}{ P* } & \multirow{2}{*}{$\begin{array}{c}\text { Homojenlik } \\
\text { Varsayımı }\end{array}$} & \multirow{2}{*}{ HipoteZ } & \multicolumn{4}{|c|}{ Anova } & \multirow{2}{*}{$\begin{array}{r}\text { HipoteZ } \\
\text { Kararl }\end{array}$} \\
\hline & & & & & & F & sd1 & $\mathrm{sd} 2$ & $p^{*}$ & \\
\hline 1.160 & 5 & 413 & 0.114 & Geçerli & $\mathrm{H}_{01}$ & 2.355 & 5 & 413 & 0.060 & Kabul \\
\hline 0.511 & 5 & 413 & 0.400 & Geçerli & $\mathrm{H}_{02}$ & 0.688 & 5 & 413 & 0.683 & Kabul \\
\hline 1.045 & 5 & 413 & 0.123 & Geçerli & $\mathrm{H}_{03}$ & 3.123 & 5 & 413 & 0.009 & Red \\
\hline 1.213 & 5 & 413 & 0.159 & Geçerli & $\mathrm{H}_{04}$ & 1.246 & 5 & 413 & 0.291 & Kabul \\
\hline 0.058 & 5 & 413 & 0.728 & Geçerli & $\mathrm{H}_{05}$ & 2.281 & 5 & 413 & 0.060 & Kabul \\
\hline 1.056 & 5 & 413 & 0.383 & Geçerli & $\mathrm{H}_{06}$ & 3.056 & 5 & 413 & 0.017 & Red \\
\hline 1.790 & 5 & 413 & 0.105 & Geçerli & $\mathrm{H}_{07}$ & 1.874 & 5 & 413 & 0.133 & Kabul \\
\hline 1.029 & 5 & 413 & 0.982 & Geçerli & $\mathrm{H}_{08}$ & 4.544 & 5 & 413 & 0.004 & Red \\
\hline 1.740 & 5 & 413 & 0.368 & Geçerli & $\mathrm{H}_{09}$ & 7.023 & 5 & 413 & 0.000 & Red \\
\hline
\end{tabular}

**\% 5 anlam seviyesinde 
Tablo 6'daki levene test istatistiğine ait olasılık (p) değerlerin tamamı 0.05 'den büyük olduğu için " $\mathrm{H}_{0}$ : Grup varyansları homojendir (eşittir)" şeklinde kurulan sıfir hipotezi kabul edilmiştir, yani tüm hipotezler için homojenlik varsayımı geçerlidir. Bunun sonucu olarak anova test istatistiği için kurulan hipotezlerin yorumları sağlıklı olacaktı. Tablo 6'ya göre $\mathrm{H}_{03}, \mathrm{H}_{06}, \mathrm{H}_{08}$ ve $\mathrm{H}_{09}$ hipotezler reddedilmiștir. Bunun anlamı " $\mathrm{H}_{03}$ : Yaş grupları bakımından F3'e iliş̧in görüş farkl1lığ1 yoktur", " $\mathrm{H}_{06}$ : Meslek grupları bakımından F3'e ilişkin görüş farklılığ1 yoktur", "H $\mathrm{H}_{08}$ : Mezun olunan gruplar bakımından F2'ye ilişkin görüş farklılığ 1 yoktur ve " $\mathrm{H}_{09}$ : Mezun olunan gruplar bakımından F3'e ilişkin görüş farklılığ yoktur" hipotezlerinin alternatifi olan hipotezler kabul edilerek, gruplar aras1 farklılıkların olduğu söylenir. Farklılı̆̆ın hangi gruplardan kaynaklandığını görmek için "Post Hoc" testlerine başvurulur Bu tür çalışmalarda en çok kullanılan post hoc testi "Tukey test istatistiği" yapılarak farklılıkların kaynağı araştırılmıştır.

Buna göre;

$\mathrm{H}_{\mathrm{A} 3}$ : Yaş grupları bakımından $\mathrm{F} 3$ 'e ilişkin görüş farklılı̆̆ vardır, alternatif hipotezine ait post hoc sonucu olarak 18-24 ve 25-31 yaş grupları 53 ve üzeri yaş grubuna göre F3 faktörüne bakış açıları arasında anlamlı bir farklılık vardır. 18-24 ve 25-31yaş grup ortalamaları 53 ve üzeri yaş grup ortalamasından büyüktür.

$\mathrm{H}_{\mathrm{A} 6}$ : Meslek grupları bakımından F3'e ilişkin görüş farklılığı vardır, alternatif hipotezine ait post hoc sonucu olarak hekim/doktor meslek grubu ile hemşire/ebe meslek grup arasında F3 faktörüne bakış açıları arasında anlamlı bir farklı1ık vardır. Hekim/doktor meslek grubu ortalaması hemşire/ebe meslek grup ortalamasindan büyüktür.

$\mathrm{H}_{\mathrm{A} 8}$ : Mezuniyet derece gruplar bakımından F2'ye ilişkin görüş farklılı̆g 1 vardır, alternatif hipotezine ait post hoc sonucu olarak lise mezun grubu ön lisan/lisans ve yüksek lisans/doktora mezunu gruplardan F2 faktörüne bakış açıları arasında anlamlı bir farklılık vardır. Lise mezun grubun ortalaması ön lisan/lisans ve yüksek lisans/doktora mezun grupları ortalamasından düşüktür.

$\mathrm{H}_{\mathrm{A} 9}$ : Mezuniyet derece gruplar bakımından F3'e ilişkin görüş farklılığı vardır, alternatif hipotezine ait post hoc sonucu olarak ilköğretim mezunları ile lise ve ön lisans/ lisans mezun grupları arasında, ön lisans/lisans mezun grubu ile de yüksek lisans/doktora mezun grubu arasında F3 faktörüne bakış açıları arasında anlamlı bir farklılık vardır. İlköğretim mezunlarının ortalaması lise ve ön lisans/ lisans mezun grup ortalamasından düşük iken ön lisans/lisans mezun grup ortalaması yüksek lisans/doktora mezun grup ortalamasından yüksektir.

\section{SONUÇ}

İSG konusunda uzman kişilerin de görüşü alınıp geçerliliği sağlanarak hazırlanan anketin Cronbach Alpha değeri 0.927 'dir. Anketin ilk kısmında (8 soru) katılımcılara ait bilgilere yer verilmiştir. Anketin ikinci kısmından (22 soru için) elde edilen veri matrisine ait Kaiser-Meyer-Olkin (KMO) test değerinin (0.943) 0.60'den büyük olması, veri matrisinin faktör analizi için uygun olduğunu göstermektedir. $\mathrm{Bu}$ çalışmada faktör sayısı üç olarak belirlenmiştir. $\mathrm{Bu}$ üç 
faktörün daha kolay yorumlanabilmesi ve isimlendirilmesi amaciyla Varimax Rotasyon dönüştürme işlemi yapılmıştır. Bu işlem sonucunda faktörlerin toplam varyansın \% 63.212'sini açıkladığı görülmüştür. Katılımcılara göre en önemli faktör "Güvenlik Kuralları" faktörüdür. Bu faktör toplam varyansın yaklaşık \% 25'ini açıklamaktadır. Demografik değişkenlerden cinsiyet bakımından "Güvenlik Kuralları" faktörüne ilişkin görüşlerde erkek katılımcılardan kaynaklanan bir farklılık görülmüştür. Buna göre "Güvenlik Kuralları" faktörünün erkek katılımcılar üzerinde olumlu bir etkisinin bulunmadığ 1 belirlenmiştir. Katılımcıların yaş grupları, meslek grupları ve mezuniyet derece grupları dikkate alındığında "Güvenlik Eğitim" faktörüne ilişkin değerlendirmelerinde farklılıklar görülmüştür. Aynı zamanda mezuniyet derece gruplarının "Güvenlik İletişimi” faktörüne ilişkin tutumlarında da farklılıklar görülmüştür.

\section{KAYNAKÇA}

Arpat, B. (2015). Işsgüvenliği Kültürünün İş kazalarına Etkileri: Metal Sektörü-Denizli İli Örneği, Yayımlanmamış Doktora Tezi, Sakarya: Sakarya Üniversitesi Sosyal Bilimler Enstitüsü

Başbuğ, A. (2013). İsyerlerinde İş Să̆gl̆ğ ve Güvenliği. Ankara: Şeker-İş Sendikası.

Bilir, N. (2016). İş Sağlığı ve Güvenliği, İstanbul: Güneş Tıp Kitapevleri

Bulut, A. (2016). 112 Acil Durum Ambulanslarinda ISG Risklerinin Tespiti ve ISG Rehberi, Ankara: Çalışma ve Sosyal Güvenlik Bakanlığı İş Sağlığı ve Güvenliği Uzmanlık Tezi, https://www.ailevecalisma.gov.tr/media/1356/alpaybulut.pdf (01.02.2019)

Burke, M.J., Caitlin E.S.S. (2016). Safety Trainig, The Wiley Blackwell Handbook of the Psychology of Occupational Safety and Workplace Health, Ed. by Sharon Clarke, Tahira M. Probst, Frank Guldenmund, Jonathan Passmore, England: West Sussex, John Wiley\&Sons, Ltd

Ceylan, H. (2012). Türkiye'deki İş Sağlığı ve Güvenliği Eğitimi Sorunlar ve Çözüm Önerileri, $\begin{array}{lllll}\text { Electronic Journal of Vocational Colleges, } & \text { V.2 }\end{array}$ https://dergipark.org.tr/download/article-file/62602 (01.02.2019)

Demirbilek, T. (2005). İş Güvenliği Kültürü̈, İzmir: Dokuz Eylül Yayınları.

Demirbilek, T. (2015). Işs Güvenliği, İzmir: İlkem Ofset

Devebakan, N., (2007). Özel Sağllk Isşletmelerinde Işs Sağll̆ğ ve Güvenliği. Yayımlanmamış Doktora Tezi, İzmir, Dokuz Eylül Üniversitesi Sosyal Bilimler Enstitüsü.

European Agency for Safety and Health at Work (EASH) (2011), Occupational Safety and Health Culture Assessment, https://osha.europa.eu/en/tools-and- publications/publications/ reports/culture_assessment_soar_TEWE11005ENN(01.02.2019)

Gürbüz, S. ve Şahin, F. (2014). Sosyal Bilimlerde Araştırma Yöntemleri. Ankara: Seçkin Yayıncilik.

Hair J.F., Black W.C, Babin B.J., \& Anderson R.E. (1998). Multivariate Data Analysis, Prentice Hall, 365.

Kabakçı, M. (2013). 6331 Sayılı Kanun'un İş Sağlığı ve Güvenliği Anlayışı ve Risklerden Korunma İlkeleri (m.5) İşlevi, Sicil İş Hukuku Dergisi, İstanbul: MESS Yayını, Sayı:29

Kılkış, İ. (2018). İs Sağlığ ve Güvenliği Hukuku, Bursa: Dora Yayıncılık

Özkan, Ö., Emiroğlu, O.N., (2006). Hastane Sağlık Çalışanlarına Yönelik İşçi Sağlı̆̆ı ve İş Güvenliği Hizmetleri, Cumhuriyet Üniversitesi Hemşireli Yüksekokulu Dergisi, 10 (3): 43-51.

Özkan, Y. ve Arpat, B. (2015). Mavi Yakalılarda Güvenlik Kültürü Algısı: Denizli İli Kablo İmalat Endüstrisi Örneği, http://www.siyasetekonomiyonetim.org/index.php/seyad/article/view /312 (01.02.2019) 
Öztürk, H. ve Babacan, E. (2012). Hastanede Çalışan Sağlık Personelinin İş Güvenliği, Gümüşhane Üniversitesi Sağlik Bilimleri Dergisi, http://dergipark.ulakbim.gov.tr/gumussagbil /article/view/5000003594/5000004108 (01.02.2019)

Saraç, Ç. (2016). İş Sağlı̆ğ ve Güvenlik Kültürü Algısının İş Tatmini ile İlişkisinin İncelenmesi. Nişantaşı Üniversitesi, Yayımlanmamış Yüksek Lisans Tezi, İstanbul.

Serin, G. ve Çuhadar, M. T. (2015). İş Güvenliği ve Sağlığı Yönetim Sistemi, SDÜ Teknik Bilimler Dergisi, 5 (2): 44-59

Seyhan, G. (2015). İş Sağlı̆̆ ve Güvenliği Yönetim Sistemi, İzmir: İlya Yayıncılık.

Şahin, L. A. (2017). Sağlık Çalışanın İş Sağlığı Güvenliği ve İş Stresi. Gaziantep Üniversitesi Sağlık Bilimleri Enstitüsü Yüksek Lisans Tezi

Taşdemir, R., Oğuzöncül, A.F., Bengü Durmuş, B., (2015). Hastaneleri Fiziki Yapısının Yatan Hastaların Memnuniyet Düzeyleri Üzerine Etkisi, Sağlıkta Performans ve Kalite Dergisi, (10): $1-12$

Tüzüner, V.L., Özaslan, B.Ö., (2011). Hastanelerde İş Sağlı̆̆ı ve Güvenliği Uygulamalarının Değerlendirilmesine Yönelik Bir Araştırma, Ístanbul Üniversitesi İşletme Fakültesi Dergisi, 40 (2): 138-154.

Yegin, A. (2015), İ̧s Güvenliği Kültürünün Işs Kazalarına Etkileri, Yayımlanmamış Yüksek Lisans Tezi, İstanbul: Gedik Üniversitesi Sosyal Bilimler Enstitüsü, İstanbul.

Yorgun S. ve Atasoy A. (2013). Hemşirelerin Çalışan Sağlığı ve Güvenliği Kültürü Algılarının Çalışan Sağlığı ve Güvenliği Kültürü Ölçeği Kullanılarak İncelenmesi, https://dosyahastane.saglik.gov.tr/Eklenti/9857,13-hemsirelerin-calisan-sagligi-veguvenligi-kulturu-algilarinin-calisan-sagligi-ve-guvenligi-kulturu-olcegi-kullanilarakincelenmesipdf.pdf?0 (01.02.2019)

\section{SUMMARY}

2.3 million workers die annually due to occupational accidents and occupational diseases in the world. More than 337 million occupational accidents per year increase absenteeism. The economic dimension of this drama is also frightening. The cost of inadequate occupational health and safety (OHS) practices is estimated to be $4 \%$ of the annual gross domestic product on a country-by-country basis. When many studies and statistical data are evaluated, it is seen that the occurrence of occupational diseases is largely due to the fact that workers are not sufficiently trained and unconscious about occupational health and safety. Within the framework of the preventive approach that is accepted in the field of occupational health and safety in the world in recent years, the issue of receiving the necessary trainings for the protection of the employees from the risks in the workplace has become one of the subjects that are considered at the top of the international law level.

One of the main causes of occupational accidents or diseases is that workers are not trained in the workplace risks and do not have sufficient awareness of the importance of training. Occupational health and safety training refers to the planned and scheduled training activities given to the employees in order to provide them with awareness of safe behavior and to increase their knowledge and skills related to their jobs. The basic function of OHS trainings; to create awareness of occupational accidents and occupational diseases.

OHS training is seen as one of the tools used to prevent and reduce workplace accidents and occupational diseases. OHS training is a planned activity aimed at achieving the specific objectives of occupational health and safety and 
acquiring new knowledge and skills primarily. In the recent period, OHS trainings constitute an important application step within the framework of the importance given to the formation of international awareness and safety culture. Through the education, the information obtained from the person can be converted into practice and behavioral change can be achieved and correct behavioral models regarding occupational health and safety can be revealed.

In the justification of the Occupational Health and Safety Law no. 6331, which was prepared within the framework of EU and ILO norms and entered into force on 30.06.2012, education is the most effective method for ensuring the occupational health and safety of the employees, As a result of the development and training of employees about occupational health and safety, the aim is to create a healthy and safe working environment by reducing occupational accidents and occupational diseases. Article 17 of Law No. 6331 regulates the training of employees, one of the obligations of the employer.

In our study, private hospital employees who have an important place in health sector are exposed to biological, chemical, physical and psychosocial risks while providing health services. As in the international legislation, the works in healthcare establishments are defined in the "very dangerous class" group. Consequently, the consequences of occupational accidents and occupational diseases in health enterprises sometimes lead to more serious consequences than occupational accidents and occupational diseases in different sectors. The relevant statistics show that the rate of occurrence of occupational accidents and occupational diseases in health enterprises is higher than many sectors. Risks faced by healthcare professionals in the service delivery processes threaten patients as well as healthcare professionals in general

In the survey participants; It is seen that OHS and safety culture assessment scores related to OHS scale and its sub-dimensions increase with age. It was observed that the OHS culture scores obtained were higher in favor of men. In order to achieve an increase in OHS culture for women, OHS culture activities for women should be increased. It was observed that the marital status of the participants did not contribute significantly to OHS culture scores.

When the effect of education level on OHS culture is examined, it is seen that OHS culture scores are lower in associate degree graduates. It was observed that occupational groups did not have a significant effect on OHS culture scores and that OHS culture scores were lower in the nurse / midwife group.

When the participants are examined according to their professional experiences, it is seen that the time spent in the profession has a positive effect on OHS culture. When the general result of the study is considered, it is found that OHS trainings in private hospitals create a positive OHS culture and consequently a safety culture phenomenon in almost all employees and the importance given to the subject in private hospitals is significantly higher. 